ISSN: 2318-1966

v. 1, n. 2

Jan -Jun 2014

\title{
Dossiê
}

\section{IDEOLOGIA: REVISÃO DE UM CONCEITO PERTINENTE AOS ESTUDOS SOBRE DIVULGAÇÃO CIENTÍFICA EM MUSEUS}

\section{Ideology: review of a concept relevant to studies of science divulgation in \\ museums}

\author{
Daniel Maurício Viana de Souza \\ Professor do Departamento de Museologia, Conservação e Restauro \\ Universidade Federal de Pelotas.
}

\begin{abstract}
RESUMO
O termo ideologia possui múltiplas e contraditórias significações. Sua profunda polissemia the permitiu apropriações diversificadas ao longo do tempo, fazendo com que assumisse contornos e funções difusas e dispersas, sempre de acordo com as demandas específicas de cada contexto em que é empregado. Este artigo trata sobre o conceito de ideologia, procurando refletir - ainda que de forma breve - sobre a sua pertinência no âmbito concreto dos museus, sobretudo os de ciência, em suas atividades de divulgação científica. Apresentaremos uma síntese dos diversos significados que foram atribuídos à ideologia, desde o seu surgimento até os dias atuais. Dentre as diversas correntes do conhecimento dedicadas ao estudo dos quadros ideológicos, optamos por privilegiar a perspectiva de John B. Thompson, em virtude de resguardar potencial para contribuir de maneira consistente com o debate atual presente nos estudos sociológicos concernentes à divulgação científica e à memória social da ciência, em especial, operacionalizada em museus.

Palavras-chave: Ideologia; Museus; Divulgação Científica; Memória Social; John B. Thompson
\end{abstract}

\begin{abstract}
The term ideology has multiple and contradictory meanings. Its deep polysemy allowed it to have various appropriations over time, causing them to assume diffuse and scattered roles and characteristics, always according to the specific demands of each context in which it is used. This article discusses the concept of ideology, seeking to reflect - albeit briefly - on their relevance in the concrete context of museums, especially science, in their scientific disclosure activities. It presents a synthesis of the various meanings that have been attributed to ideology, from its inception to the present day. Among the various fields of knowledge dedicated to the study of ideological frameworks, we chose to focus on the perspective of John B. Thompson, by virtue of to contain potential to contribute in a consistent manner with the current debate in these sociological studies concerning the scientific dissemination and social memory of science particularly operationalized in museums.
\end{abstract}

Keywords: Ideology; Museums; Scientific Divulgation; Social Memory; John B. Thompson 


\section{NORUS v1, n.2, jan-jun 2014.}

\section{INTRODUÇÃO}

A menção ao termo ideologia implica no tratamento de concepções que encerram diversificadas, e muitas vezes, até contraditórias significações. Em virtude desta multiplicidade semântica, que também se manifesta como imprecisão conceitual, tal noção vem sendo apropriada em contextos igualmente heterogêneos, sempre em resposta a demandas específicas. Considerada por John B. Thompson (1995), como um conjunto de significações que influenciam nas perspectivas simbólicas presentes na criação, legitimação e manutenção de relações desiguais de interesses, a ideologia estaria, portanto, inter-relacionada com a ciência. Frequentemente revestida pela "legalidade" do discurso "verdadeiro", apoiado na "razão", a ciência estaria sempre cercada pela ideologia e seus aspectos de intencionalidade no interior de relações econômicas, políticas e culturais específicas.

De acordo com Lumbreras Salcedo (1988), não existe museu sem conteúdos, e “(...) a memória está sujeita a diversos níveis de operação, que mantêm espaços diferenciados de presença de informação, que podem ser manifestos ou encobertos, segundo as circunstâncias das ações e seus condicionantes históricos e sociais". Na qualidade de instâncias de representação da memória social, os museus de ciência por meio de suas exposições se constituem espaços para produção de significados basilares da memória científica.

Tais perspectivas apontariam, assim, para a existência de uma vinculação intrínseca entre os aspectos ideológicos de estabelecimento e sustentação de relações específicas de interesses e os processos informacionais em curso nos museus de ciência. A divulgação científica implementada nas exposições museológicas de cunho científico, da mesma maneira, contribuiria para a construção de uma imagem social da ciência recortada de modo a periferizar diversos aspectos característicos da sua heterogênea configuração social.

Apresentaremos, inicialmente, uma síntese dos diversos significados que foram atribuídos ao termo ideologia, desde o seu surgimento até os dias atuais. Dentre as diversas correntes do conhecimento dedicadas ao estudo dos quadros ideológicos, optamos por privilegiar a perspectiva sociológica de Thompson em virtude de sua compatibilidade e atualidade no que tange aos aspectos da divulgação científica operada nos museus de ciência.

É importante evidenciar que se trata aqui de propor uma reflexão de cunho eminentemente teórico, de forma que, o modelo de abordagem thompsoniano opera como um 


\section{Ideologia: revisão de um conceito pertinente aos estudos sobre divulgação científica em museus}

tipo ideal capaz de apreender um recorte representativo da realidade concreta do universo museológico científico, que conforme sabemos, é complexa e heterogênea. De maneira que, a representatividade do grupo - ou amostra, se assim preferirmos - dos fenômenos descritos no momento em que se expõe a aplicabilidade da formulação teórica do sociólogo norte-americano, por mais que se encontre em um nível de abstração considerável, está respaldada tanto na literatura científica disponível, quanto na nossa própria experiência acadêmica e profissional na área dos museus e da divulgação científica.

\section{DE CIÊNCIA À FALSA CONSCIÊNCIA: CONCEITOS E NOÇÕES DE IDEOLOGIA}

As concepções sobre as ideias, como elementos capazes de moldar e deformar aspectos e relações específicas de interesse, atuando sobre o processo de elaboração do conhecimento, remetem à Antiguidade grega. Aristóteles, ao elaborar uma espécie de teoria geral que explicaria a realidade e suas transformações - que na cosmologia medieval ficou conhecida como "teoria das quatro causas" - investia na tentativa de sistematização do conhecimento grego. Tal fato representaria, segundo Chauí (1980, p. 5), o gérmen do pensamento ideológico, considerado como a tentativa de "tomar as ideias como independentes da realidade histórica e social, de modo a fazer com que tais ideias expliquem aquela realidade, quando na verdade é essa realidade que torna compreensíveis as ideias elaboradas."

Ainda durante o Renascimento, Bacon (1982) alertava para a necessidade de livrar os homens das "noções falsas" que permeavam a alma dos seres através de "ídolos" - formas de "pseudo-verdades" legitimadas pelo poder das tradições. Porém o termo ideologia, propriamente dito, só foi empregado pela primeira vez em finais do século XVIII por Destutt De Tracy (1970), a fim de significar uma "ciência da gênese das ideias". Nesse contexto, permeado pelas concepções Iluministas de anseio de um mundo transparente e livre de qualquer preconceito e crenças supersticiosas - que só poderia ser alcançado através do pensamento racional e científico - a ideologia seria esta ciência racional, capaz de investigar as leis que regem as possibilidades de surgimento e desenvolvimento das ideias.

Um novo segmento de pensadores, políticos e entusiastas em geral da "ciência das ideias", os denominados "ideólogos" franceses, surge no início do século XIX como defensores e propagadores da mais recente crença absoluta no progresso científico enquanto caminho único 


\section{NORUS v1, n.2, jan-jun 2014.}

para a liberdade e para a construção de uma "sociedade verdadeira". Esses "ideólogos" pertenciam ao partido liberal francês e se colocavam contrários a todo e qualquer tipo de respaldo metafísico ou divino que - como se costumava considerar - balizava o poder monárquico e religioso. Inicialmente, os "ideólogos" foram partidários de Napoleão por considerarem-no um homem portador de fortes preceitos liberais e continuador dos ideais da Revolução Francesa. De modo que em determinados períodos do seu governo, inúmeros "ideólogos" foram nomeados em cargos de grande prestígio e caráter estratégico, prestando-lhe serviços intelectuais com vistas à construção de pressupostos teóricos propícios à sua legitimação no poder - sempre com bases em critérios supostamente "científicos" e "racionais".

Todavia, o rompimento de Bonaparte com os "ideólogos", por conta da declarada oposição às leis de segurança do Estado, entre outras querelas políticas, militares e econômicas, tornam-se marcos históricos no que se refere ao caráter pejorativo do termo ideologia, que vai prevalecer durante as décadas seguintes. ${ }^{1}$ Durante o período que compreendeu a passagem do século XVIII para o XIX, algumas reflexões acerca da categoria "sujeito" elaboradas por Kant e Hegel - então, os principais filósofos da corrente do "idealismo clássico" - mostraram-se fundamentais no aprofundamento da questão da ideologia sob uma abordagem crítica (KONDER, 2000, p. 24). Segundo Kant (1986), todo conhecimento é sempre uma construção subjetiva, de maneira que, mesmo quando se age por causas objetivas, não existem possibilidades de serem ignoradas motivações e interesses próprios e subjetivos. Hegel (1992), por seu turno, adverte que a verdade jamais pode ser alcançada no seu todo através de um contato apriorístico. Isto se deve ao fato de que a condição do humano, enquanto sujeito social conectado diretamente à formação e transformação da consciência política, estaria ligada à história das modificações institucionais.

As reflexões acima descritas contribuíram para que o termo ideologia fosse gradualmente deixando de "denotar um cético materialismo científico para significar uma esfera de ideias abstratas e desconexas, e é este o significado da palavra que será então adotado por Marx e Engels" (EAGLETON, 1997, p. 71). De sua utilização primeira às apropriações na atualidade, à ideologia, de acordo com Eagleton (1997, p. 15-16), foi proposto um sem número de definições e conceituações: produção de significados, signos e valores sociais; corpo de ideias de um

\footnotetext{
1 “Todas as desgraças que afligem nossa bela França devem ser atribuídas à ideologia, essa tenebrosa metafísica que, buscando com sutilezas as causas primeiras, quer fundar sobre suas bases a legislação dos povos, em vez de adaptar as leis ao conhecimento do coração humano e às lições da história" (Discurso de Napoleão ao Conselho de Estado em 1812 apud Chauí, 1980, p. 10).
} 


\section{Ideologia: revisão de um conceito pertinente aos estudos sobre divulgação científica em museus}

determinado grupo social; ideias legitimadoras de um poder político dominante; ideias falsas, que legitimam poderes políticos; comunicação simultaneamente distorcida; formas de pensamento motivas por interesses sociais específicos; pensamento de identidade; ilusão socialmente necessária; conjuntura de discurso e poder; confusão entre realidade linguística e realidade fenomenal; processo de conversão da vida social em realidade natural; conjunto de crenças com vistas à ação; oclusão semiótica e muitos outros.

No quadro proposto por Eagleton (1997), apresentado acima, destaca-se a inexistência de uma coerência conceitual, de maneira que incompatibilidades e mesmo contradições são comuns no que tange às tentativas de definição do que possa vir a ser ideologia. $\mathrm{O}$ termo por vezes fará menção a referências ilusórias e distorcidas de uma dada realidade ou fenômeno; em contrapartida, o encontraremos referindo-se a modos, ideias e visões racionais de uma determinada parcela, segmento ou fração social.

Frente a esta abrangência conceitual que pode ser atribuída à ideologia, Konder (2002, p. 10) sugere que podemos, grosso modo, agrupar as várias definições em dois metagrupos distintos: o primeiro denotaria um "significado fraco" designando "sistemas de crença políticas, conjuntos de ideias e valores cuja função é orientar comportamentos coletivos relacionados à ordem pública". O segundo, relativo ao "significado forte" da expressão ideologia que, por seu turno, faria referência a "uma distorção no conhecimento". A primeira destas duas acepções atribui ares de neutralidade ao termo ideologia, enquanto o último ponto de vista apresenta-se crítico e, de alguma maneira, reforça o caráter negativo do conceito. O importante diante desta perspectiva é reconhecer que a(s) ideologia(s), em sua dilatação conceitual infindável, possui empregos segundo diferentes contextos, pontos de vista e aplicações. Não fazer essas distinções, todavia, pode ser - e segundo Konder, o foi durante a história - alvo de uma série de imprecisões e apropriações convenientes.

Dentre os que consideram a ideologia sob seu "significado forte", encontram-se os pensadores que seguem as correntes da tradição marxista, na qual este conceito estaria de modo geral vinculado às condições materiais de produção na sociedade capitalista, inserida na dinâmica das relações humanas. Em “A Ideologia Alemã”(Ano), Marx e Engels propõem uma revisão da filosofia hegeliana, no sentido de tornar evidente os pressupostos do que viria a se constituir o "materialismo histórico" em oposição à perspectiva "idealista" dos "ideólogos alemães". Na obra de Marx (Ano) a questão da ideologia encontra-se vinculada à categoria "alienação" em termos 


\section{NORUS v1, n.2, jan-jun 2014.}

de um não reconhecimento, por parte do trabalhador explorado, da totalidade de sua produção diferentemente da obra de Hegel, na qual relaciona-se ao "Espírito"2.

Em referência à postura de Marx, Eagleton (1997, p. 78) argumenta que a própria produção das condições materiais e espirituais, inserida no contexto da alienação, seria pressuposto para a existência da humanidade - o que subjugaria a própria consciência, pois seria ela mesma, elaborada sob a égide das relações sociais de produção:

Se os poderes e instituições humanas podem ser submetidos a esse processo, então a consciência também pode. A consciência está, na verdade, estreitamente vinculada à prática social; no entanto, para os filósofos idealistas alemães de que falam Marx e Engels, ela se torna dissociada dessa prática, fetichizada a uma coisa-em-si, e assim, mediante um processo de inversão, pode ser erroneamente compreendida como a própria origem e fundamento da vida histórica. Se as ideias são apreendidas como entidades autônomas, então isso ajuda a naturalizálas e desistoricizá-las; e esse é, para o jovem Marx, o segredo de toda a ideologia (1997, p. 71).

A partir deste ponto de vista, seria possível argumentar que a consciência individual se torna secundária frente a uma espécie de "consciência social" que, na percepção de Mészáros (2004, p. 65), é a expressão própria da ideologia na prática de construção e validação de critérios que suprimem a realidade conflituosa da sociedade de classes perpetuando a ordem já estabelecida. O alcance das implicações práticas de tal forma de "consciência social" seria possível pela disposição de mecanismos econômicos, culturais, políticos variados, além ainda da importância das teorias e práticas científicas, assim como as "diversas filosofias e autorreflexões da ciência referentes à sua função reguladora no complexo total das atividades humanas" (2004, p. 116).

Na análise de Eagleton (1997, p. 78), Marx, ao vincular a questão da ideologia, enquanto elemento superestrutural, às ideias dominantes representando "formas ilusórias", tal como é feito em um primeiro momento de sua obra, cometeria uma contradição, uma vez que essas "formas codificam lutas reais". Assim sendo, pergunta o autor: “em que sentido seriam ilusórias?” Mais adiante, Marx - sobretudo em “O Capital”(Ano) - não faz qualquer referência à ideologia enquanto "formas ilusórias", abandonando o caráter irreal ou fantasioso da superestrutura. Dessa

2 Segundo Hegel, "Espírito" está relacionado à "Razão" enquanto essência do próprio "Ser" em suas várias manifestações no mundo da "Natureza" e da "Cultura". Na filosofia hegeliana é preciso compreender a noção de "História" como um "progresso" que caminha em direção ao "Espírito" em sua plenitude: o "Espírito Absoluto" (PACINI, 1973, p. 25). 


\section{Ideologia: revisão de um conceito pertinente aos estudos sobre divulgação científica em museus}

maneira, há uma ampliação da definição de ideologia abrangendo "todos os homens, não só a classe dominante" (Autor, ano, p. 79). Anteriormente a ideologia em Marx era proposta como especulação idealista reduzida ao horizonte da "falsa consciência", agora ela se ancora de maneira consistente em representações materiais das práticas sociais burguesas.

Mesmo na obra de Marx, como é possível notar, existe uma grande polissemia - por vezes compreendida mesmo como indefinição - quanto ao que se estaria referindo exatamente com o emprego do termo ideologia. Este aspecto caracteriza, segundo Eagleton (1997), um ponto central de fragilidade na teoria da ideologia marxista, deixando lacunas onde seriam estabelecidas possibilidades de leituras das mais diversas e até mesmo pouco claras, refletindo conflitos entre os significados epistemológicos e políticos do termo ideologia.

A questão da ciência, por exemplo, é representativa da inconsistência conceitual do termo ideologia no bojo da tradição marxista. Na grande maioria das vezes a ciência aparece relacionada aos meios de apresentação e validação das ideias dominantes, através de seus critérios pretensamente balizados pela neutralidade e objetividade incontestáveis. Considerando, por outro lado, a existência de uma realidade "intrinsecamente traidora" - tal como aparece em “O Capital”, dentre outras obras do próprio Marx - "é necessário então um discurso especial, conhecido como ciência, para penetrar nas suas formas fenomenais e desnudar suas essências" (autor, ano, p. 87). Neste sentido, somente a "ciência do materialismo histórico" poderia se contrapor à ideologia dominante.

Não é incomum encontrarmos na literatura marxista leituras que podem ser consideradas um tanto diferentes das concepções do próprio Marx, configurando-se assim, muitas vezes em adulterações do pensamento deste autor. No que se refere à questão da ideologia, especificamente, o quadro não é diferente. É possível listar uma série de interpretações acerca deste conceito, no decorrer do século XX, que são em diversas ocasiões bastante diversas da perspectiva marxiana, chegado a ser às vezes, até mesmo contraditórias. A seguir, descreveremos de forma concisa, como na ótica de alguns dos principais autores de extração marxista se apresenta o conceito de ideologia.

Embora não estivesse preocupado com o conceito de ideologia em si, Lenin (2007) contribui nesta discussão quando afirma que existem duas ideologias que se contrapunham no capitalismo, a proletária e a burguesa, e é fundamental deter-se na análise acerca do confronto entre estas duas ideologias. É importante notar que, após tal proposição leninista, o termo 


\section{NORUS v1, n.2, jan-jun 2014.}

ideologia passa a ser colocado como referência a qualquer posicionamento de classe, afastando-se assim, da conotação necessariamente pejorativa que tinha no pensamento marxiano. Por este mesmo motivo, Lenin (1982) chega a fazer referência à proximidade existente entre ideologia e ciência, ao identificar o próprio ideal revolucionário como um instrumental tecnicamente organizado e com potencial de mobilização e convencimento das massas.

Posteriormente, os escritos de Georg Lukács sobre a noção de 'reificação', representaram uma grande contribuição para o debate sobre a questão da ideologia. Segundo o autor, a fonte de distorção ideológica na sociedade burguesa é a percepção empírica que os trabalhadores têm da realidade em que vivem e trabalham. Tal distorção deve ser superada por uma "consciência possível”, capaz de propiciar à classe operária o processo de totalização (LUKÁCS, 1989, p. 313). A superação da ideologia burguesa comprometida com a coisificação, portanto, deveria se dar através do reconhecimento de que os objetos sociais não são coisas, mas relações entre homens. Devemos notar que da década de 1930 em diante, Lukács abandona alguns aspectos da concepção de ideologia adotada até então, passando a considerar - assim como já havia feito Lenin - as divergências bipolares desta noção. É importante notar, porém, que diferente do revolucionário russo, Lukács (1968, p. 85) antagonizava radicalmente ciência e ideologia. Dessa forma, a ciência (revolucionária) é a via que torna possível apreender a realidade, a partir da particularidade. Diferente da ideologia, que só nos faz ver uma "realidade" que é apologética dos interesses da burguesia.

Profundamente influenciada pelas concepções lukacsianas, a noção de ideologia em Karl Mannheim está intimamente ligada à questão da ciência, no bojo de sua empreitada de construção de uma sociologia do conhecimento. Em sua clássica obra "Ideologia e Utopia", de 1929, a argumentação acerca do conceito de ideologia leva em conta a necessidade de um reconhecimento mais efetivo da fecundidade da diversidade de ângulos para se alcançar uma visão mais abrangente da realidade. As ideologias são, de acordo com o autor (1986, p. 66), sempre conservadoras, expressando o interesse da classe dominante na estabilização da ordem. Importante ressaltar que, de acordo com a perspectiva de Mannheim, "está implícito na palavra ideologia a noção de que, em certas situações, o inconsciente coletivo de certos grupos obscurece a condição real da sociedade". Ainda que, por outro lado, a "utopia" seja o contraponto da ideologia conservadora, ambas tendem a uma certa unilateralidade, que deriva do fato de que o 


\section{Ideologia: revisão de um conceito pertinente aos estudos sobre divulgação científica em museus}

pensamento de todos os grupos emerge de suas condições de vida e se liga às circunstâncias daqueles que estão pensando.

Quanto ao debate sobre a relação ideologia-ciência, Mannheim chama atenção para a necessidade de reconhecer a inevitável presença de "valores" na perspectiva científica - um reconhecimento crítico, a saber. Propõe-se nestes termos, um novo tipo de objetividade científica, não mais sustentada na exclusão de valorizações, mas na percepção e no controle crítico destas. É preciso advertir, contudo, que num primeiro momento do pensamento do sociólogo húngaro, ideologia e ciência eram essencialmente antagônicas, de forma que, atribuía-se o fenômeno da ideologia aos que se "equivocaram" em contrapor-se ao conhecimento científico, portanto, verdadeiro (Ano, p. 104). Já num momento posterior, há o reconhecimento de que as distorções ideológicas derivavam das condições sociais e atingiam a toda sociedade. Enfim, para Mannheim, o marxismo errava ao atribuir a possibilidade de objetividade do conhecimento a uma determinada classe social, o proletariado. Ao propor o sujeito do "intelectual relativamente desvinculado" como alternativa à classe operária, o autor estaria tentando apresentar uma via ideal que não era nem a ideologia nem a utopia, mas as ideias "propriamente científicas".

A interpretação de alguns dos principais expoentes da Escola de Frankfurt sobre a ideologia é notadamente diferenciada em comparação a perspectiva de Mannheim. Max Horkheimer, por exemplo, argumentava que nas sociedades capitalistas os sujeitos, quaisquer que fossem suas posições de classe, não podiam se apoiar numa razão "transparente a si mesma", toda camada social pode apresentar uma consciência ideologicamente distorcida e corrompida (1983, p. 133). "Dialética do Esclarecimento", produzido em coautoria com Theodor Adorno, parte de uma crítica aprofundada do Iluminismo e ao seu corolário "espírito esclarecedor" que se manifesta no séc. XVIII, mas também vivamente na atualidade. A pretensão do pensamento "esclarecido" de identificar e fazer prevalecer a verdade sobre os mitos e os preconceitos, é segundo os autores (2006, p. 18) abusiva. De forma que em nome dessa "verdade" erigiu-se novos preconceitos e forjou-se novos mitos, que seriam signos da contradição, camuflados pela "ilusão de harmonia", por sua vez, caracterizando a forma dominante de ideologia na vida cultual, a "indústria cultural". Em obra posterior, Adorno (2001, p. 27) adverte ao fato de a falsidade da ideologia ser mais perigosa, na medida em que ela alimenta a pretensão de corresponder à realidade. Pretensão que se fortalece ao máximo quando o sujeito é induzido a crer que alcançou uma visão global satisfatória. 


\section{NORUS v1, n.2, jan-jun 2014.}

Herbert Marcuse partilhava a crítica de Adorno e Horkheimer ao totalitarismo e ao liberalismo, observando que a única "igualdade" que a sociedade oferecia aos indivíduos atomizados pela concorrência generalizada, era uma igualdade abstrata, que se realizava como desigualdade concreta (1982, p. 66). Assim se constituía sua noção de ideologia, que era acima de tudo "individualista", representada em uma conduta e um pensamento 'unidimensional' (Ano, p. $32)$.

Assim como Marcuse, outro representante da Escola de Frankfurt, Walter Benjamin, procurou voltar sua produção teórica para intervir de maneira prática, nos movimentos políticos embora, em grande medida, suas concepções se sustentassem em temas que apresentavam alto grau de abstração. De acordo com o autor (2008), a ação corruptora da ideologia sobre nossa consciência se dá por meio de uma história contínua, construída pela lógica do "sempre igual". As pessoas são, assim, induzidas a adotar critérios que implicam conveniência com uma certa percepção do tempo como algo linear, mecânico, homogêneo, anulador da subjetividade. Benjamin descreve, portanto, um verdadeiro sacrifício da "dimensão histórica" pela distorção ideológica do chamado "historicismo", em que as pessoas olham para o passado e são obrigadas a se identificarem com os vencedores. Ainda neste itinerário, o autor argumenta que as noções de "progresso" e "desenvolvimento" - corolários da ciência moderna - são, em última análise, ideológicas, pois, na realidade, a história se baseia no incompleto, inacabado, que é em si urgência de mudança.

Afiliado de uma geração mais recente de pensadores frankfurtianos - e também, vale dizer, mais distanciadas das concepções marxistas - Jürgen Habermas afirma, que a ideologia não precisaria mais se impor de cima pra baixo, pois funciona como se estivesse implícita na consciência da população despolitizada, não sendo assim, mais possível aplicar duas características fundamentais da teoria marxista, o conceito de luta de classes, e o próprio conceito de ideologia - ao menos não como em Marx ou no marxismo. Tal realidade, segundo o autor (1975, p. 45), se deve ao fato de que "a evolução do sistema social parece ser determinada pela lógica do progresso científico e técnico". Cria-se uma nova forma de legitimação diferente da antiga ideologia, que dispensa o recurso à ilusão de satisfação de interesses. Sua função continua sendo de evitar o questionamento dos fundamentos da sociedade, porém, por outros meios: a técnica e a ciência, de acordo com a direção da política econômica que está sendo adotada. Nesta nova prática ideológica, por consequência, a ciência passa a não se dispor mais a reflexão crítica 


\section{Ideologia: revisão de um conceito pertinente aos estudos sobre divulgação científica em museus}

sobre si mesma. É como forma de reação crítica, que Habermas (1982, p. 65) em sua teoria sobre o "agir comunicativo", propõe a busca de uma situação de comunicação "isenta de dominação".

Ainda sobre esse tema, Antonio Gramsci, aponta para a impossibilidade de contraposição entre ideologia e ciência, também determinada e localizada historicamente e sendo assim, não podendo pretender-se acima das marcas que o fluxo da história imprime. A ciência, considerada pelo pensador como parte da "superestrutura", realiza seus avanços e conquistas inserida no que ele chama de campo das "ideologias historicamente orgânicas", aonde são construídos os critérios de objetividade que a permite criar representações da realidade reconhecidas por todos, independente de qualquer ponto de vista e particularidades de classes ou frações de classes. (2001, p. 1456-1457). Diante desta constatação, Gramsci (Ano, p. 873) adverte que as representações jamais se deixam alcançar em seus contextos de criação, ao passo que as teorias científicas precisam sempre ser pensadas historicamente, em uma perspectiva do "historicismo absoluto".

Profundamente marcado pela Revolução Russa - tanto quanto Gramsci - Mikhail Bakhtin afirmava que tudo que é ideológico é um signo, comportando sempre a seguinte ambivalência: reflete (fidelidade) ou refrata (distorção) a realidade. Sua questão frente à ideologia consiste, assim, em saber "como o signo reflete e refrata a realidade em transformação" (2004, p. 41). De acordo com o autor, há signos em diferentes domínios e representações, dentre as quais a próprias formulações científicas. Na condição de signos (ideológicos), constituem-se como sistema a partir de alguma forma de organização social, considerando que, o social precede o individual, e a complexidade do mundo interior de cada sujeito depende da complexidade da organização social. Dessa maneira, a consciência individual é formada a partir da superestrutura social. Produzindo no escopo dos estudos sobre a linguagem, Bakhtin sustentava que o caminho para a investigação da ideologia avançaria através do estudo de todas as formas de fala. Segundo ele, é no que os sujeitos falam, ou nos silêncios desta fala, que se processa a criação ininterrupta da ideologia (Ano, p. 41).

Um outro autor que consideramos importante referir é Louis Althusser. Claramente reassumindo o marxismo-leninismo, afirma que o que os homens representam para si mesmos na ideologia, nunca é o mundo tal como ele efetivamente existe, e sim, a marca nele da intervenção humana (1983, p. 81). Dessa forma, o homem representa a sua relação com as suas condições reais de existência, e é essa relação que está no centro de toda representação ideológica. Nas 


\section{NORUS v1, n.2, jan-jun 2014.}

sociedades capitalistas, argumenta Althusser, as condições materiais de produção precisam ser reproduzidas, adequando-se a critérios destinados à promoção da aceitação da ideologia dominante. Tuas práticas são necessariamente operadas por um aparelho (repressor) de Estado, os “aparelhos ideológicos de Estado". Ainda de acordo com Althusser (Ano, p. 83), a ideologia é essencialmente contrária à ciência. Caberia ao discurso científico, como um "discurso sem sujeito", superar o efeito de evidência dos sujeitos, provocado em última instância, pela ideologia.

Entre os que costumam pensar a questão da ideologia de acordo com os parâmetros do que anteriormente foi aqui apresentado como seu "significado fraco", é comum considerá-la parte do todo social, onde o homem constrói e reconstrói significados para suas ações extrapolando, dessa maneira, a esfera de interesses de um único segmento da sociedade. Eagleton (1997, p. 1920) rejeita a ideia de que toda ideologia seja opressora e legitimadora, acentuando a importância de que embora a ideologia seja recoberta por impulsos identificadores e homogeneizadores, ela é "marcada e desarticulada por seu caráter "relacional", pelos interesses conflitantes entre os quais deve manobrar incessantemente" (Ano, p. 194).

O mesmo autor adverte que compreender a ideologia tão somente como elemento de legitimação de um determinado poder político, resultaria em um recorte conceitual problemático. Considerando o poder tal como Foucault (2004), algo que não se restringe aos mecanismos oficiais/estatais, mas que é difuso, tecido como uma rede de forças penetrante e invisível, podendo ser encontrado em todo e qualquer tipo de relação humana, não haveria como reduzir o significado do termo ideologia às esferas de interesses políticos dominantes. Seria então, para Eagleton (Ano), perfeitamente possível atribuir à ideologia sentido no interior de disputas de poder difusas e que "estão em toda parte" - como sugere Foucault (Ano) - reconhecendo, todavia, que tais querelas não possuem as mesmas influências e implicações nas esferas de maior pertinência estratégica, seja no âmbito econômico, político, cultural, dentre outros ${ }^{3}$.

Alguns autores que adotam a ideia de "pós-modernidade" - citados a seguir - propõem um esvaziamento da acepção radical do pensamento ideológico, no sentido de que, nesta perspectiva, diversas premissas tradicionalmente ligadas ao marxismo são sistematicamente deixadas de lado. Sob esta ótica, Lyotard (1988), procura trabalhar as relações entre ideologia e produção de conhecimento científico, considerando a reestruturação do campo intelectual

\footnotetext{
${ }^{3}$ Foucault (Ano.) acerca de tal questão admite que, embora esteja em toda parte, há poderes mais e menos centrais.
} 


\section{Ideologia: revisão de um conceito pertinente aos estudos sobre divulgação científica em museus}

ocorrida durante o atual momento histórico de enfraquecimento das possibilidades de ação das "grandes narrativas" . Este quadro implicaria principalmente na diminuição da ideologização do saber institucionalizado.

Para Baudrillard (1995), a esfera cultural, ao tornar-se autônoma de toda e qualquer representação normativa de classe pertencente ao terreno do capitalismo, influencia e determina com seus signos toda a produção material da "pós-modernidade" - o que, no marxismo clássico, fica a cargo da ideologia. Há ainda teóricos como Jameson (1996), que delegam à cultura o elemento central na regulação da sociedade "pós-moderna". Tudo nesta sociedade, segundo Jameson, seria mediado pela cultura, de forma que mesmo as esferas políticas e ideológicas estariam primeiramente prefiguradas por pressupostos e interesses meramente culturais.

Diante da multiplicidade de noções, conceitos e definições de ideologia elaboradas ao longo da história moderna é necessário reconhecer que as diversas concepções, muitas vezes incompatíveis entre si, resultam de contextos econômicos, políticos e socioculturais historicamente divergentes. Propomos apresentar na seção seguinte a perspectiva de John B. Thompson acerca do fenômeno da ideologia, procurando, de alguma maneira, introduzir os aspectos de sua argumentação no horizonte do nosso estudo a respeito da divulgação científica operada nos museus de ciência por meio de suas exposições.

\section{UMA QUESTÃO DE FORMULAÇÃO SIMBÓlICA: A IDEOLOGIA SEGUNDO THOMPSON}

Embora reconheçamos os limites da inserção de formulações ideológicas como propulsoras de valores de identidade a partir de elementos homogeneizadores, admitimos, bem como propõe Thompson (1995, p. 79), que a ideologia, em certo nível, consiste em formular subsídios simbólicos úteis para criar e manter relações de interesses e dominação. $\mathrm{O}$ referido autor propõe uma "formulação alternativa do conceito de ideologia" a partir de uma perspectiva de análise que combata o que ele considera a "neutralização da ideologia": concepções que não denotam um sentido pejorativo, à parte de qualquer valoração ou intenções ilusórias vinculadas a grupos de interesses em particular. Ideologia, neste sentido, é mais um dentre os demais aspectos

\footnotetext{
4 Em sua obra Lyotard compreende como "grandes narrativas" o poder do Cristianismo, o Humanismo, o Iluminismo, o Romantismo, o Nazismo, o Marxismo dentre outras.
} 


\section{NORUS v1, n.2, jan-jun 2014.}

da vida social, podendo "estar presente, por exemplo, em qualquer programa político, independente de estar ele orientado para a revolução, a restauração ou reforma, independentemente de desejar a transformação ou a preservação da ordem social” (Ano, p. 7273).

Em contraposição as “concepções neutras” de ideologia - tal como postulado por Konder (Ano), - Thompson refere-se às "concepções críticas de ideologia" como as que se debruçam sobre o fenômeno ideológico encarando-os de maneira negativa a partir de uma proposta crítica de análise. Ao contrário das concepções anteriores que procuravam "neutralizar" a capacidade de inserção da ideologia em relações amplas de poder, as “concepções críticas” implicam em uma vertente sempre parcial, enganadora e distorcida do elemento ideológico ${ }^{5}$. Na busca de uma formulação "alternativa do conceito de ideologia" que combata as suas perspectivas de neutralização, o autor respalda seu arcabouço investigativo na importância que assumem as “formas simbólicas" para a construção de "significados" que, de maneira geral, permearão as relações sociais.

Ao considerar que todo fenômeno ideológico é também, e essencialmente, um fenômeno simbólico $^{6}$ (Ano, p. 76), o prisma thompsoniano é desenvolvido sem a preocupação com suas possíveis manifestações errôneas e/ou ilusórias - para ele, características que não compõem a essência do fato ideológico enquanto tal, apresentando-se apenas como "possibilidades contingentes". Sua preocupação fundamental diz respeito às maneiras como as formas simbólicas se entrecruzam com determinadas relações de interesse: "Fenômenos ideológicos são fenômenos simbólicos significativos desde que eles sirvam, em circunstâncias sóciohistóricas específicas, para estabelecer e sustentar relações de dominação" (ANo, p. 76. grifo nosso).

Neste contexto de análise da ideologia, Thompson propõe-se a identificar os seguintes aspectos essenciais:

\footnotetext{
5 Dentre alguns pensadores que, ao longo da história, adotaram "concepções neutras de ideologia", segundo Thompson, podemos citar, por exemplo, De Tracy, Lenin, Lukács e Mannheim. Por outro lado, dentre os que basearam suas reflexões sobre ideologia nos parâmetros constituintes da "concepção crítica" - tal como a descrição thompsoniana - encontramos Napoleão, Marx e o próprio Mannheim em determinadas fases de sua obra.

${ }^{6}$ Tal consideração não significa que seu oposto seja também verdadeiro. Todo fenômeno ideológico é um fenômeno simbólico, porém, nem todo fenômeno simbólico é necessariamente ideológico. "Se fenômenos simbólicos servem, ou não, para estabelecer e sustentar relações de dominação, é uma questão que pode ser respondida somente quando se examina a interação de sentido e poder em circunstâncias particulares” (THOMPSON, 1995, p. 76).
} 


\section{Ideologia: revisão de um conceito pertinente aos estudos sobre divulgação científica em museus}

- Sentido - refere-se ao sentido das formas simbólicas, parte integrante do meio social correspondente a uma série de atitudes e ações - linguísticas ou não - que de alguma forma são responsáveis pela construção de significados no âmbito social.

- Dominação - relaciona-se diretamente à questão do poder, nesse caso especificamente ao poder assimétrico, ou seja, “(...) quando grupos particulares de agentes possuem poder de uma maneira permanente, em grau significativo, permanecendo inacessível a outros grupos, ou a grupos de agentes" (ibid, p. 80).

Respaldado nas reflexões sobre as categorias de "sentido" e "dominação" considerando suas inter-relações na teia social, procura-se analisar de que maneira pode o sentido ou o significado agir para estabelecer e sustentar relações desiguais de interesses. Thompson (Ano) reconhece que neste caso, há um sem número de possibilidades, estratégias e formas de atuação pelas quais os sentidos podem ser mobilizados com vistas à criação e amparo de condições sóciohistóricas específicas nas quais predominam relações de desequilíbrio em sentido amplo na vida social. São identificados, nesta perspectiva, cinco principais "modos de operações gerais da ideologia" que permitem indicar ligações com circunstâncias concretas de estratégia de construção simbólica das relações sociais. Seriam elas:

- Legitimação - relações específicas podem ser sustentadas desde que pareçam inegavelmente legítimas diante de um determinado contexto. No que tange às maneiras como certas representações parecem justas e merecedoras de apoio incondicional, Thompson (Ano) remete-se a Weber (Ano) ${ }^{7}$ que distingue três fundamentos acerca dos quais os processos simbólicos de constituição e sustentação da legitimidade podem se apoiar: a) "fundamentos racionais": apelam à legalidade de parâmetros previamente estabelecidos; b) "fundamentos tradicionais": recorrem à sacralização repassada através dos tempos pelas tradições; c) "fundamentos carismáticos": apelam ao caráter excepcional de uma personalidade, idéia ou manifestação cultural.

- Dissimulação - ocultar, negar, ou mesmo desviar a atenção, são estratégias para que não se discutam as relações de interesse já estabelecidas. A "ideologia como dissimulação", na forma proposta pelo autor, lança mão de algumas estratégias simbólicas tais como: a) "deslocamento": ao referir-se a vários objetos ou pessoas utilizando o mesmo termo,

\footnotetext{
${ }^{7}$ Ver WEBER, M. Economia e sociedade: fundamentos da sociologia compreensiva. Volume 1. Brasília, EdUnb. 1991.
} 


\section{NORUS v1, n.2, jan-jun 2014.}

automaticamente deslocam-se conotações positivas ou negativas, de acordo com o interesse do uso; b) "eufemização": determinados atos, pessoas ou relações sociais são (re)descritos utilizando sutilmente elementos de eufemismo, de modo a torná-los positivos diante do interesse pretensamente geral; c) "tropo": entendido por Thompson (Ano) como o uso figurativo ou metafórico dos diversos elementos de linguagem - compreendendo também, e fundamentalmente, os seus aspectos simbólicos.

- Unificação - a partir da criação, em nível simbólico, de elementos de identificação coletiva, à parte de qualquer diferença e incompatibilidade que possa existir, são meios de preservar as relações existentes. As estratégias típicas através das quais este modo de operação ideológico se manifesta são: a) "padronização": formas simbólicas são interligadas por meio do estabelecimento de padrões que, de alguma maneira, dão a sensação de fácil compartilhamento entre membros de um determinado grupo; b) "simbolização da unidade": objetiva construir elos efetivos de unidade, identidade e identificação coletiva, por meio de elementos simbólicos manipulados e difundidos no interior de grupamentos sociais, que por força de seus contextos de constituição e desenvolvimento, são plurais, diversos e heterogêneos.

- Fragmentação - ao contrário da forma anterior, relações dominantes podem continuar estabelecidas criando formas simbólicas de segmentação e afastamento do "outro", do "diferente", daquele que "não pertence". A intenção por trás do uso desta operação ideológica, na percepção de Thompson, é quase sempre afastar manifestações, pessoas e ideias que representam algum tipo de ameaça ou desafiam, de alguma forma, as relações de poder e interesses já estabelecidas. Tais esforços de "esvaziamento" do potencial de alteração de um quadro convenientemente constituído, utilizam-se da estratégia simbólica da "diferenciação": aquela que reforça os traços das distinções e divisões de modo a provocar a desunião e o afastamento que vão impedir qualquer estruturação de uma ação voltada para a mudança. Outra tática simbólica empregada neste sentido é o "expurgo do outro", onde a construção de uma imagem negativa e perigosa de alguém ou alguma coisa motiva os demais membros de um grupo a rechaçarem o elemento ameaçador da ordem em vigor.

- Reificação - produzir a sensação de naturalidade e consequentemente de intransitoriedade de uma determinada situação histórica-transitória-específica, é também um meio para manter as relações vigentes. A ideologia como reificação retrata processos enquanto coisas e, de acordo com a estratégia simbólica da "naturalização", atribui a acontecimentos, 


\section{Ideologia: revisão de um conceito pertinente aos estudos sobre divulgação científica em museus}

ideias e fenômenos dimensões quase imanentes "de modo que seu caráter social e histórico é eclipsado" (Ano, p. 87). A tática simbólica semelhante da "eternização" é responsável por cristalizar na vida social aspectos de permanência a partir da banalização de signos de tradição recortados do processo histórico como um todo.

\section{O MUSEU COMO DIFUSOR IDEOLÓGICO DA MEMÓRIA CIENTÍFICA}

Os museus de ciência, ao tratarem de fenômenos e pressupostos científicos, utilizam os elementos materiais tridimensionais para implementar a comunicação com o público visitante. Nestas instituições, as construções informacionais advindas de premissas do conhecimento científico encontram na exposição museológica um meio peculiar para a divulgação científica, característica esta que se deve à ênfase e à instrumentalização dada ao objeto musealizado. Toda construção expositiva segue perspectivas operacionais que variam de acordo com as diversas tipologias de museus, mas que de maneira geral visam torná-las “(...) composições cujos elementos encontram-se dispostos num espaço predeterminado, harmonicamente conjugados para transmitir a um grupo de pessoas uma determinada mensagem, com fins culturais" (SCHEINER, 1991, p. 1).

De maneira geral, o ato de expor objetos implica conectar intrinsecamente o museu a "uma realidade que se prende ao social, território onde além da difusão cultural e outras ações, promove a produção e circulação de significados" (LOUREIRO, 2003, p. 90). Na órbita específica dos museus de ciência os quadros teóricos e operacionais que ocorrerem nas exposições configuram-se de maneira a articular o discurso museológico e as estratégias de divulgação voltadas à circulação da informação científica e tecnológica para o público em geral. A exposição, neste sentido, seria segundo Ventura (2001, p. 188), "uma obra construída a partir de negociações entre os elementos de uma rede de cultura científica, tecnológica e técnica”, onde se procura adequar narrativas acerca do saber científico através dos diversos aparatos infocomunicacionais e estratégias expositivas.

$\mathrm{Na}$ busca por promover - ao menos em tese - um diálogo reflexivo com o público acerca das relações entre ciência e sociedade, vem se lançando mão dos mais diversos aparatos infocomunicacionais e estratégias expográficas, de maneira a tornar mais acessível a narrativa 


\section{NORUS v1, n.2, jan-jun 2014.}

especializada e fechada da ciência. Apesar da perspectiva defendida por alguns autores ${ }^{8}$, segundo a qual os chamados "museus de terceira geração"9 vêm imprimindo maior dinamismo e criatividade na prática da divulgação científica, tal modelo institucional tem sido alvo de intensas críticas que os colocam lado a lado com os, assim considerados, museus de ciência tradicionais no que se refere às suas orientações ideológicas de cunho cultural e político. Tais críticas costumam estar baseadas no argumento de que as novas técnicas de apresentação e recursos expográficos de operacionalização das coleções científicas, ao privilegiarem o potencial da interatividade, dão demasiada ênfase no entretenimento e na diversão, acarretando numa severa fragmentação e descontextualização dos princípios da ciência, deslocando-os da trama social.

A adoção de linguagens interativas tem sido um dos caminhos mais utilizados para estimular uma participação efetiva do público alvo da divulgação científica operada em museus de ciência. O caráter interativo das exposições nestas instituições seria, segundo Saad (1998, p.22), seu recurso principal, o que delineia seu perfil na contemporaneidade. Contudo, ainda há calorosas discussões quanto às reais possibilidades participativas e educacionais da interatividade. As críticas mais consistentes baseiam-se em dois argumentos fundamentais: 1) por muitas vezes o que se postula como uma ação interativa, não chega a passar de simples "reatividade", ou seja, aparatos do tipo push-botton, por meio dos quais a participação do visitante se limita a apertar um botão e ver o que acontece; 2) a ênfase dispensada, em um número considerável de exemplos - se não for mesmo na maioria dos casos - na exposição de produtos e resultados da ciência, desconectados de uma contextualização, ou mesmo uma apresentação histórica e sociocultural. Desta maneira Falcão (1999, p. 34) adverte que a interatividade aplicada como "garantia de êxito e qualidade na comunicação com o visitante", por si só, não se sustenta.

\footnotetext{
${ }^{8}$ Ver, por exemplo, Cavalcanti; Persechini (2011) e Valente, Cazelli, Alves (2005).

${ }^{9}$ As diferentes abordagens disciplinares acerca do museu de ciência apresentam contornos pouco delimitados no que diz respeito às suas variações conceituais e práticas. O "International Council of Museums" (ICOM) propõe dois comitês referentes aos espaços museológicos dedicados à ciência em duas perspectivas: "Museus de História Natural" e "Museus de Ciência e Técnica". Em função das diferentes transformações desses dois tipos de museus científicos considera-se como Museu de Ciência e Técnica toda e qualquer instituição dedicada à divulgação científica. (LOURENÇO, 2000; MOSCOVICH, 1963; CIALDEA, 1994; KOSTER, 1998). Além destas delimitações conceituais, porém, diversos autores, como Bragança Gil (1988) e Padilla (1998), por exemplo, propõe uma classificação tipológica dos museus de ciência expressa em "gerações". Os "museus de $3^{\mathrm{a}}$ geração" se caracterizariam principalmente por focar na temática dos fenômenos e conceitos científicos, considerando seus contextos sócio-políticos e históricos, promovendo a comunicação com o público através de abordagens interativas.
} 


\section{Ideologia: revisão de um conceito pertinente aos estudos sobre divulgação científica em museus}

As narrativas expositivas dos museus de ciência, via divulgação científica, pretendem-se capazes de promover diálogos e reflexões acerca das relações entre ciência e sociedade. Existiriam, entretanto, aspectos da divulgação da informação de vulto científico em tais instituições que apontariam para uma apresentação acrítica da ciência, onde faltariam, segundo Marandino (2005, p.163), maiores considerações acerca dos embates ideológicos presentes em suas construções e relações com o meio social. As exposições em museus de ciência entendidas como "unidades pedagógicas, em que ocorrem processos de recontextualização do discurso científico", não deixam de implicar muitas vezes no erro da "espetacularização", da construção de imagens "a-históricas", "a-políticas" e descontextualizadas da ciência, tecnologia e seus produtos (Ano, p. 178).

A categoria "transposição museográfica", por vezes também chamada de "transposição expositiva", é uma adaptação operada por Marandino (Ano) do conceito de "transposição didática" elaborada por Chevallard (1991), ao universo das exposições museológicas de ciência. Trata-se da adequação do saber científico às linguagens expográficas que implicariam em algumas consequências descritas como

- Descontemporalização: o saber divulgado é retirado de seu tempo de origem e separado de seu contexto histórico;

- Naturalização: o saber é recoberto com status de evidência incontestável;

- Descontextualização: mais que uma retirada do contexto original, o saber sofre recontextualizações de acordo com as pretensões do discurso expositivo;

- Despersonalização: o saber desvincula-se do agente produtor, ligando-se a novos horizontes de intenção (CHEVALLARD, 1991 apud MARANDINO, 2005, p. 171).

Os museus de ciência, dessa maneira, vêm atuando como espaços de preservação, gestão e divulgação da ciência, por meio de suas exposições, constituindo loci para a construção de significados, que de certo modo, contribuiriam para delinear os contornos da memória científica. A partir desta perspectiva, existiriam questões fundamentais que apontariam para uma ligação estreita entre os aspectos ideológicos de estabelecimento e legitimação de relações desiguais de interesses e a informação construída e resignificada através dos objetos musealizados na qualidade de representantes legítimos do patrimônio científico.

Acreditando no respaldo que a abordagem thompsoniana pode oferecer sobre a problemática da ideologia relacionada à ciência e a divulgação científica, abordaremos, em 


\section{NORUS v1, n.2, jan-jun 2014.}

seguida, as especificidades e implicações do fenômeno ideológico no interior do espaço musealizado de ciência. Neste contexto, serão fundamentais para esta reflexão, as premissas desenvolvidas no que tange aos modus operandi pelos quais relações específicas de interesses são construídas, mantidas e disseminadas. É possível relacionar aqui - ainda que de maneira breve e introdutória - tais preceitos às perspectivas museológicas. Chamamos a atenção, contudo, ao fato de que, na ausência de dados de campo - em função das limitações deste formato paper, e também, dos objetivos de reflexão teórica, aqui propostos ${ }^{10}$ - procuramos nesta empreitada aplicar o modelo esquemático de Thompson e organizar a argumentação, de forma a abarcar da maneira mais íntegra possível a heterogeneidade das especificidades empíricas concernentes aos fenômenos ora tomados como objeto.

Os aspectos da "ideologia enquanto legitimação", operando por meio dos "fundamentos tradicionais", relacionam-se com a atividade museológica sobretudo no que se refere a questão da memória. O caráter documental/evidente repassado através dos tempos pelas tradições, atribuídas a determinados elementos constituintes da memória de um país, grupo social, ou qualquer tipo de atividade humana - como a ciência, por exemplo - constitui-se em construções simbólicas operadas nos museus, que cristalizam relações específicas de interesse. Dessa maneira, objetos musealizados balizadores das estruturas discursivas museológicas, tornam-se representantes de uma dada realidade que se apresenta legitimada pelos valores da tradição e, portanto, não apresenta motivos para ser (re)pensada e (re)discutida.

Ainda no que tange aos aspectos da operação ideológica nos espaços museais por via da "legitimação", os "fundamentos carismáticos" apontados por Thompson se encontram presentes nos museus, caracterizando os esforços de criação de imagens de excepcionalidade de pessoas, feitos, culturas, dentre outros aspectos que constituirão os quadros de uma memória plasmada por idealizações de singularidade e extraordinariedade. Sendo assim, certos elementos ou relações são legítimas no interior de um determinado contexto por seus contornos peculiares constituintes de um perfil merecedor de reverência e não de contestação.

\footnotetext{
10 Sublinhado que toda a argumentação, aqui desenvolvida, encontra-se fundamentada em elaborações empíricas presentes em pesquisas e estudos, resultantes da nossa prática acadêmica e profissional. Acreditamos, ainda, que comprometer-se em demonstrar empiricamente os pressupostos teóricos ora formulados, implicaria necessariamente em uma descrição ilustrativa e análise aprofundada de ao menos uma exposição museológica de ciência - senão, de diversas. Sendo assim, entendemos que este texto não é o espaço mais apropriado para tal enfoque - considerando, sobretudo, as limitações e objetivos já explicitados aqui.
} 


\section{Ideologia: revisão de um conceito pertinente aos estudos sobre divulgação científica em museus}

A "ideologia enquanto dissimulação", na qualidade de "ferramenta simbólica" de ocultamento, negação, e desvio de atenção, encontrar-se-ia presente nos museus fundamentalmente operando através da estratégia da "eufemização". A apresentação da "informação/objeto musealizado" descrevendo atos, pessoas e relações sociais de maneira a atribuírem aspectos valorativos de positividade, caracterizaria um eufemismo útil para estabelecer e sustentar relações de interesses.

O modo de operação ideológica por meio da "unificação", por possuir características pretensamente identificadoras no interior de uma coletividade, tem relação direta com os aspectos do patrimônio - elemento presente em grande parte das instituições de memória, como é o caso dos museus. A procura do desenvolvimento de uma linguagem padronizada de fácil reconhecimento por todos os sujeitos no âmbito de um grupo, através da interligação de elementos simbólicos, além ainda, da construção de elos efetivos de identidade coletiva por meio da manipulação dos signos e significados, caracterizam as estratégias elaboradas pela "ideologia enquanto unificação". Nos museus, esses elementos responsáveis pela criação, em nível simbólico, de elos de identificação no interior de uma coletividade - que por si só é heterogênea, conflituosa e múltipla em diversos aspectos - são constituintes do patrimônio que enquanto tal age como meio de construção e preservação de uma memória - ou, em termos thompsonianos, age como meio de estabelecimento e manutenção de uma conjuntura de interesses.

O modo de operação ideológico contrário ao descrito acima, a "fragmentação", ocorre em museus quando se utiliza de signos/patrimônio de segmentação com vistas à construção de significados auto-valorativos em face das manifestações daqueles que estão em situação de alteridade, ou não partilham dos mesmos pressupostos de relações de interesses já estabelecidas. Por meio de estratégias como "diferenciação" e "expurgo do outro" a "ideologia enquanto fragmentação" manifestada em espaços museológicos, reflete a tentativa de "esvaziar" pensamentos, ideais e interesses diversos que de maneira geral, possam representar ameaças, desafios ou resistências às estruturas existentes.

As sensações de naturalidade e imutabilidade de uma situação que é específica de um contexto histórico e social, elaboradas ideologicamente pela "reificação", são perspectivas que podem ser operadas em instituições museológicas de ciência por meio, fundamentalmente, de

suas exposições. A ciência, em suas formas simbólicas de sobrevalorização inspiradas em pressupostos "cientificistas" onde aparece como atividade humana privilegiada para produção de 


\section{NORUS v1, n.2, jan-jun 2014.}

discursos com "contornos inelutáveis de verdade", posicionando-se acima de qualquer interesse que não seja a própria "Verdade", se encontra plasmada pela estratégia ideológica de "naturalização" que lhe agrega atributos de uma pseudo-imanência.

As exposições museológicas de ciência, na qualidade de espaços de divulgação cientifica, podem contribuir ideologicamente para a cristalização de aspectos de permanência de relações de interesses ocorridas no âmbito da ciência, através da estratégia da "eternização". Naturalizando signos que cooperaram para a extensão de relações específicas de poder e interesses recortados do contexto sócio-histórico como um todo no qual se dá a atividade científica, a divulgação operada nas exposições museológicas além de construir uma imagem eterna de uma situação não mais que conjuntural, colabora no tratamento de processos enquanto "coisas".

\section{CONSIDERAÇÕES GERAIS}

O afastamento da imagem de inter-relação da ciência com os múltiplos aspectos sociais, representa uma forma de estabelecer e sustentar relações de interesse e dominação, seja no âmbito científico, seja em qualquer outra esfera balizada pelos pressupostos do discurso da ciência. Tais perspectivas são implementadas nas exposições em museus de ciência, através da instrumentalização da "informação/objeto musealizado", operando (re)significações da linguagem semântica presente no patrimônio científico. Assim considerando, tais práticas de divulgação científica executadas por essas instituições museológicas contribuiriam para o traço característico da ideologia de intercruzamento de formas simbólicas com determinadas relações de interesse.

As exposições realizadas em museus de ciência são exemplos de práticas de divulgação científica que podem contribuir em vários aspectos para o estabelecimento e sustentação de relações específicas de interesse e poder. Por meio da operacionalização do objeto musealizado, representante legítimo do patrimônio científico e ao mesmo tempo elemento simbólico de sobrevalorização da ciência, tais exposições são emblemáticas quanto à presença de aspectos ideológicos de:

- legitimação de valores científicos e culturais respaldados numa memória instituída, referentes aos "avanços" em áreas específicas da ciência, com vistas ao progresso social; 


\section{Ideologia: revisão de um conceito pertinente aos estudos sobre divulgação científica em museus}

- dissimulação de interesses específicos, que são motivadores de episódios históricos, por meio de descrições atribuidoras de valores de positividade a personagens, seus atos e suas relações;

- unificação, a partir da postulada "educação patrimonial", criando elos de identificação no interior da trama sociocultural que estaria representada no objeto musealizado, exposta ao público em geral. Existem, desta maneira, simbolizações da unidade através da imposição dos valores identitários presentes no patrimônio, sem um aprofundamento quanto aos contextos de criação e atuação destes objetos;

- reificação da ciência sob pressupostos "cientificistas", como atividade privilegiada na produção de discursos prescritivos com contornos irrefutáveis de verdade apontando para o progresso social. Objetos representativos da história da ciência, expostos sem o cuidado de uma contextualização mais abrangente, incorrem na construção de uma imagem "naturalizada" da ciência posicionando-a acima de qualquer interesse que não esteja direcionado à "Verdade".

As diversas instituições museológicas de ciência, tanto do Brasil como no restante do mundo, seguem uma tendência herdeira das transformações ocorridas após a Segunda Guerra Mundial, que postula como um de seus principais objetivos, possibilitar a percepção da presença da ciência e da tecnologia através de seus produtos e resultados relacionando-se com o cotidiano social. Por outro lado, a divulgação científica implementada sem a preocupação com as diversas etapas do processo de construção da ciência, além de encobrir seus aspectos de provisoriedade contribui para uma configuração ideológica, pautada apenas nos seus resultados. O acesso à ciência e à tecnologia fica mais especificamente restrito aos resultados que poderão, de alguma maneira, implicar em uma instrumentalização ou uma aplicação comprometida em "civilizar" de acordo com os seus parâmetros de "avanço" e "evolução".

Uma das principais formas de manifestação da ideologia nas exposições museológicas enquanto instrumentos de divulgação científica dá-se através da apresentação de um "produto fechado" em detrimento das disputas, interesses e conflitos presentes no processo de construção do conhecimento científico. A informação assim produzida nos museus de ciência corresponderia a reduções "reflexivas" das relações sociais, recortando e estabelecendo significados que possam cumprir o papel ideológico de fundação e/ou manutenção de relações específicas de poder e/ou interesses. 


\section{NORUS v1, n.2, jan-jun 2014.}

A informação científica nos espaços expositivos museológicos cumpre, desta maneira, o papel ideológico de criação de subsídios simbólicos, contribuindo para a construção de valores específicos referentes à ciência, amplamente difundidos através de uma divulgação científica criticamente "estéril" que colabora na formação de uma audiência mais estimulada pela curiosidade do que pela reflexão. A divulgação científica operada nos museus de ciência somente pode se aproximar do cumprimento de seus objetivos pretendidos de contribuição ao acréscimo da qualidade de vida por meio do acesso e compreensão ampla da ciência e da tecnologia, criando meios para que se perceba a inserção intrínseca dos processos de construção dos produtos e saberes científicos na trama sócio histórica. É necessário também deixar claro que os discursos científicos refletem ideologicamente interesses do próprio universo da ciência, implicando diretamente no contexto social.

\section{REFERÊNCIAS}

ADORNO, Theodor. Prismas. São Paulo: Ática, 2001.

. W.; HORKHEIMER, M.;. A Dialética do esclarecimento: fragmentos filosóficos. Rio de Janeiro: Jorge Zahar Ed., 2006.

ALTHUSSER, Louis. Aparelhos Ideológicos de Estado. Rio de Janeiro: Graal, 1983.

BACON, Francis. "Novum organum”. In: Bacon. São Paulo: Nova Cultural, 1982. Coleção Os Pensadores.

BAKHTIN, Mikhail. Marxismo e filosofia da linguagem: problemas fundamentais do método sociológico na ciência da linguagem. São Paulo: Hucitec, 2004.

BAUDRILlARD, Jean. A Sociedade de Consumo. Lisboa: Edições 70, 1995.

BENJAMIN, Walter. Obras escolhidas: Magia e técnica, arte e política: ensaios sobre literatura e história da cultura. Brasília: Ed. Brasiliense, 2008.

BRAGANÇA GIL, Fernando. Museus de ciência: preparação do futuro, memória do passado. Colóquio Ciências, Revista da Cultura Científica, n 3, p. 74, out./1988.

CHAUÍ, Marilena. O que é ideologia? São Paulo: Ed. Brasiliense, 1980. Coleção Primeiros Passos.

CHEVALLARD, Y. La transposición didáctica: del saber sabio al saber enseñado. Buenos Aires: Aique, 1991. 
Ideologia: revisão de um conceito pertinente aos estudos sobre divulgação científica em museus

CIALDEA, R. Some future museological problems. In: ., CIALDEA, D. (eds.) The Future for Museum of Science and Technology. (Atas do encontro do CIMUSET, Roma, 8 a 15 e Setembro de 1991), p. 46-59. Roma: Universitá degli Studi di Roma "La Sapienza".

DE TRACY, Destutt. Élémens d'Idéologie. Paris: Librairie Philosophique J. Vrin, 1970.

EAGLETON, Terry. Ideologia. Uma Introdução. São Paulo: UNESP/Boitempo, 1997.

FALCÃO, Douglas. A Interatividade nos Museus de Ciências - Mesa Redonda. In: VI Reunião da Rede de Popularização da Ciência e Tecnologia na America Latina e Caribe (REDPOP), 1999, Rio de Janeiro, 1999.

FOUCAULT, Michel. Vigiar e punir. Petrópolis: Vozes, 2004.

GRAMSCI, Antonio. Cadernos do cárcere. Rio de Janeiro: Civilização Brasileira, v. 2, 2001.

HABERMAS, Jürgen. Técnica e ciência enquanto ideologia. In: Escola de Frankfurt. Os Pensadores, XLVIII. São Paulo: Abril Cultural, 1975.

1982.

. Teoria de la acción comunicativa: complementos y estúdios previos. Madrid: Cátedra,

HEGEL, Georg W. F. Fenomenologia do Espírito. In: Hegel. São Paulo: Nova Cultura, 1992. Coleção Os Pensadores.

HORKHEIMER, Max. Teoria Tradicional e Teoria Crítica. In: BENJAMIN, Walter, HORKHEIMER, Max, ADORNO, Theodor W., HABERMAS, Jürgen. Textos escolhidos. Coleção. Os Pensadores, Vo. XLVIII. São Paulo: Abril Cultural, 1983.

ICOM. International Committee for Museums and Collections of Natural History; CIMUSET International Committee of Museums of Science and Technology.

JAMESON, Frederic. Pós-modernismo: A lógica cultural do capitalismo tardio. São Paulo: Ática, 1996.

KANT, Immanuel. Idéia de uma história universal de um ponto de vista cosmopolita. São Paulo: Brasiliense, 1986.

KONDER, Leandro. A questão da ideologia. São Paulo: Companhia das Letras, 2002.

KOSTER, E. H. Vers une éducation scientifique et technique permanente. In: SCHIELE, B. (eds.). La révolution dans la Muséologies des Sciences. Colléction Muséologies, Multimondes/Presses Unicersitaires de Lyon. p. 141-157.

LÊNIN, Vladimir. Obras Escolhidas. 3 tomos. São Paulo: Alfa-Ômega, 1982.

. O Imperialismo. Fase superior do capitalismo. Brasília: Nova Palavra, 2007. 
LOUREIRO, José Mauro M. Museus de ciência, divulgação científica e hegemonia. Ciência da Informação, Brasília: IBICT, v.32, n.1, p. 88-98, jan./abr. 2003.

LOURENÇO, Marta C.C. Museus de Ciência e Técnica: que objectos? 2000. Dissertação (Mestrado em Museologia e Património) - Departamento de Antropologia da Faculdade de Ciências Sociais e Humanas, Universidade Nova de Lisboa, Lisboa. Orientador: Fernando Bragança Gil.

LUKACS, Georg. Introdução a uma estética marxista: sobre a categoria da particularidade. Rio de Janeiro: Civilização Brasileira, 1968.

. História e Consciência de Classe. Rio de Janeiro: Elfos, 1989.

LUMBRERAS SALCEDO, Luís Guillermo. Museu Nacional. In: Seminário sobre museus nacionais: perfil e perspectivas. 20-24 jun., 1988, Rio de Janeiro, SPHAN/Pró-Memória. Mimeo.

LYOTARD, Jean-François. O Pós-moderno. $3^{\text {a }}$ ed. Rio de Janeiro: José Olympio, 1988.

MANNHEIM, Karl. Ideologia e Utopia. Rio de Janeiro: Guanabara, 1986.

MARANDINO, Mharta. A pesquisa e a produção de saberes nos museus de ciência. In: História, Ciências, Saúde: Manguinhos. V. 1, n. 1 (jul-ago 1994). Rio de Janeiro: Fundação Oswaldo Cruz, Casa de Oswaldo Cruz, 2005.

MARCUSE, Herbert. A ideologia da sociedade industrial. Rio de Janeiro: Zahar, 1982.

MARX, Karl; ENGELS, Friedrich. A Ideologia Alemã (Feuerbach). São Paulo: Hucitec, 2002.

MÉSZÁROS, István. O Poder da Ideologia. São Paulo: Boitempo Editorial, 2004.

MOSCOVICH, I. Science museums in modern education. In: Museum Haaretz Bulletin. P. 4853. Tel Aviv: 1963

PACINI, Dante. Política e direito (filosofia e ciência): analítica de uma nova filosofia da política e do direito na sociedade tecnológica e industrial do futuro. Rio de Janeiro: Borsoi, 1973.

PADILlA, J. Museos y centros de Ciencia en México. In: Reunião Anual da Sociedade Brasileira para o Progresso da Ciência, 50. Natal, 1998.

SAAD, Faud Daher. Centros de Ciências: as atuais vitrinas do mundo da difusão científica. In: CRESTANA, M, CASTRO, M, PEREIRA, G. (orgs.) Centros e museus de ciência: visões e experiências: subsídios para um programa nacional de popularização da ciência. São Paulo: Estação Ciência, 1998.

SCHEINER, Tereza C. M. Museus e exposições (apontamentos para uma teoria do sentir). In: Seminário A Linguagem da Exposição, out, 1991, Suíça: Comitê Internacional de Museologia do ICOM (ICOFOM), 1991. 
Ideologia: revisão de um conceito pertinente aos estudos sobre divulgação científica em museus

THOMPSON, John B. Ideologia e cultura moderna - Teoria crítica na era dos meios de comunicação de massa. São Paulo: Vozes, 1995.

VENTURA, Paulo Cezar Santos. Exposição de objetos científicos e técnicos: de uma obra de concepção a uma obra do visitante. In: Anais do Encontro sobre a Pesquisa em Educação, Comunicação e Divulgação Científica em Museus. Rio de Janeiro, 2001. 